Research Article

\title{
Green Synthesis of Piperine/Triton X-I00/ Silver Nanoconjugates: Antimicrobial Activity and Cytotoxicity
}

\author{
Muthusamy Prabakaran ${ }^{1}$, Vellaikannu Kalaiarasi ${ }^{2}$, Periakaruppan Nithya ${ }^{1}$, Mani Gajendiran $^{3}$, \\ Susaimanickam Arul Antony ${ }^{1}$ \\ ${ }^{1} \mathrm{PG}$ and Research Department of Chemistry, Presidency College, Chennai-600005, India. \\ ${ }^{2}$ Department of Chemistry, Karpaga Vinayaga College of Engineering and Technology, Palayanoor, Maduranthakam, Chennai- \\ 603308, India. \\ ${ }^{3}$ Department of Chemistry, Vels University (VISTAS), Pallavaram, Chennai-600117, India. \\ C Corresponding authors. E-mail: gajendiran.sbs@velsuniv.ac.in; antonypresidency@gmail.com; Tel.: +91-9444240597
}

Received: Mar. 30, 2017; Accepted: May 10, 2018; Published: May 17, 2018.

Citation: Muthusamy Prabakaran, Vellaikannu Kalaiarasi, Periakaruppan Nithya, Mani Gajendiran, and Susaimanickam Arul Antony, Green Synthesis of Piperine/Triton X-100/Silver Nanoconjugates: Antimicrobial Activity and Cytotoxicity. Nano Biomed. Eng., 20I8, I0(2): I4I-I48. DOI: 10.5101/nbe.v10i2.p141-148.

\begin{abstract}
Silver nanoparticles (AgNPs) were synthesized through a green chemical approach using the piperine isolated from black pepper. The physicochemical properties of Triton X-100 coated silver nanoparticles (Triton X-100/Ag NPs) were well characterized by ultraviolet-visible absorption spectroscopy (UV-Vis), powder X-ray diffraction (PXRD), transmission electron microscopy (TEM), selected area electron diffraction (SAED) and energy dispersive X-ray spectroscopy (EDS). The TEM images confirmed the spherical shape of silver nanoparticles. The powder X-ray diffraction analysis revealed the silver nanoparticles exhibiting face-centered cubic (fcc) crystal structure with an average crystallite size of $15 \mathrm{~nm}$. The cytotoxicity effects on HepG2 cells were also evaluated with a series of 3-(4,5-dimethylthiazolyl-2)-2,5-diphenyltetrazolium bromide (MTT) assay. The effective toxic concentration of Triton X-100/piperine with silver nanoparticles was too low to damage HepG2 cells. The antibacterial activity results showed that the Triton X-100/piperine/AgNPs efficiently inhibited the two bacteria namely S. aureus and E. coli. The Triton X-100/piperine/AgNPs nanoconjugates were effective in inhibiting the growth of both gram-positive and gram-negative bacteria $S$. aureus and $E$. coli.
\end{abstract}

Keywords: Silver nanoparticles; Piperine; Triton X-100; Antibacterial activity; Green synthesis

\section{Introduction}

Silver nanoparticles (AgNPs) have attracted a great deal of attention in the last few years owing to their broad-spectrum antimicrobial activity [1, 2]. As an antibacterial agent, they are widely applied in biological and medical fields, such as wound healing
[3]. The dramatic expansion of their applications gives rise to the requirement to investigate the potential toxic effects of AgNPs towards the human body as well as on the environment [4]. It is reported in previous studies that AgNPs could induce cytotoxicity in human cells via the generation of reactive oxygen species or an increase in intracellular oxidative stress $[5,6]$. 
Therefore, it is essential to develop a green method for the synthesis of AgNPs with low cytotoxicity. According to the principles of green chemistry. The green synthesis of AgNPs should employ environmentally friendly solvents and non-toxic chemicals as reducing and stabilizing agents $[7,8]$. In addition, it has been confirmed that stabilizing agents play critical roles in biocompatibility and toxicity by influencing the surface properties of AgNPs [9]. Recently, the naturally obtained green chemicals have been widely used to synthesis the metal nanoparticles [10-12]. Various natural products such as alkaloids, phenolic compounds, saponins and flavonoids have been isolated from the black pepper [13, 14]. The extracted natural products from the black pepper have shown the antioxidant property [15]. These alkaloids such as piperine could act as reducing agents and free radical scavengers [16]. Thus, the naturally obtained alkaloids could be used as a reducing agent for the synthesis of AgNPs [17].

The nonionic surfactant micelles are fit perfectly with the definition of an ideal matrix, which stabilize the nanoparticles (NPs). Among the various types of matrices such as micelles, organic small molecules, mesoporous materials, linear polymers and dendritic polymers, the nonionic surfactant micelles are one of the most useful classes of matrices [18, 19]. However, one of the disadvantages is their toxicity that arises from the nature of the capping agents used to obtain narrow size distribution and well dispersion in aqueous medium. Some of the issues have been addressed in the recent past through establishing new surfactant and reaction conditions by using nonionic surfactant Triton X-100, which was documented as nontoxic surfactant [20]. The methodology employed here is very simple, easy to perform, inexpensive and eco-friendly. Since the Triton X-100/piperine/silver nanoconjugates were derived by green chemical method using the naturally obtained piperine as a reducing agent, the nanoconjugates could be utilized for biomedical applications without any toxicity. The Triton X-100 is also a biocompatible nonionic surfactant and it could effectively stabilize the AgNPs to yield uniformly distributed AgNPs. Hence, the Triton-X100/piperine/silver nanoconjugates have more advantages when compared to silver nanoconjugates synthesized by the conventional method or by green chemical method without using Triton X-100 as a stabilizing agent [21, 22].

In this present study, the Triton X-100-coated AgNPs (Triton X-100-AgNPs) were synthesized by a green chemical method. A series of cytotoxicity assays were performed in vitro to confirm the safe concentration range of Triton X-100-AgNPs as an antimicrobial agent for biomedical applications.

\section{Experimental Method Materials}

$\mathrm{AgNO}_{3}$ and Triton X-100 of analytical grade were purchased from Sigma Aldrich and were used as such without further purification. The black pepper corns were purchased from a local market, washed to remove any impurities, dried under sunlight to completely remove the moisture and grinded in a mixer grinder.

\section{Characterization techniques}

The ultraviolet-visible spectroscopy (UV-Vis) spectra were recorded on a UV-Vis Perkin Elmer Lambda 35 double beam spectrophotometer. The morphology and size of the AgNPs were characterized by transmission electron microscopy (TEM). TEM and selected area electron diffraction (SAED) analyses were carried out on FEI-TECNAI G2 (T-30) transmission electron microscope with an accelerating voltage of $250 \mathrm{kV}$. The powder $\mathrm{X}$ - ray diffraction (PXRD) analyses were carried out on BRUKER D8 ADVANCE diffractometer. The energy dispersive $\mathrm{X}$-ray spectroscopy (EDX) analysis was carried out on a HITACHI SU6600 field emission scanning electron microscope.

\section{Isolation of piperine from black pepper}

The black pepper powder (20 g) was refluxed with $250 \mathrm{~mL}$ ethanol for $3 \mathrm{~h}$. The solution was cooled at room temperature and filtered under vacuum; the filtrate was concentrated on a water bath. $20 \mathrm{~mL}$ of alcoholic potassium hydroxide $(10 \% \mathrm{w} / \mathrm{v})$ was added to the concentrated extract solution which was then filtered under vacuum. The alcoholic solution was concentrated to $10 \mathrm{~mL}$. It was added drop wise to small pieces of ice cubes with constant stirring until precipitation completed and was kept in a freezer for 0.5 . It was filtered and recrystallized in ethyl acetate/ methanol (3:2) mixture. For recrystallization, a small portion of piperine was dissolved in ethyl acetate/ methanol (3:2) mixture in a test tube and kept in room temperature for $15 \mathrm{~min}$ and then kept in ice bath for 15 min. The piperine crystallized out as fine needles.

\section{Synthesis of silver nanoparticles}

The piperine (500 mg) was dissolved in $25 \mathrm{~mL}$ of 
ethanol and the piperine solution (0.1-0.5\%) was used for the synthesis of AgNPs using TritonX-100 (0.6 $\mathrm{mL}$ ) as the surfactant. The main role of the Triton X-100 was to act as a capping agent for AgNPs. For reduction of $\mathrm{Ag}^{+}$ions, piperine solution (0.1-0.5\%) was added to $50 \mathrm{~mL}$ of $1 \mathrm{mmol}$ aqueous $\mathrm{AgNO}_{3}$ solution and the solution mixture was heated to $80^{\circ} \mathrm{C}$. The formation of AgNPs was indicated by the appearance of yellow color. Finally, the solution was centrifuged at 14000 rpm and washed with distilled deionized (DD) water to remove the ethanol. The Triton X-100/piperine/AgNPs were dried under vacuum.

\section{Antibacterial activity}

Antibacterial activity was performed by welldiffusion method as described in literature [23]. Nutrient agar was prepared and poured in the sterilized petri-dishes and allowed to solidify. After $24 \mathrm{~h}$, growing bacterial cultures Staphylococcus aureus ( $S$. aureus) and Escherichia coli (E. coli) were swabbed on it. The test samples at various concentrations (10, $25,50,100$ and $250 \mu \mathrm{L}$ ) were loaded in the wells made by a cork borer. Tetracycline was used as control (30 $\mu \mathrm{g} / \mathrm{mL}$ ). The plates were then incubated at $37{ }^{\circ} \mathrm{C}$ for $24 \mathrm{~h}$. After incubation, the inhibition diameter was measured.

\section{In vitro cytotoxicity}

The HepG2 cells (10000 cells/well) were cultured in a 96-well plate in Dulbecco's modified Eagle's medium (DMEM) and the sample at various concentrations was added to the cells in different groups of wells. The cultures were incubated for $24 \mathrm{~h}$ under dark at 37 ${ }^{\circ} \mathrm{C}$. After the incubation period, the cell viability of Hep-G2 cells was assessed by 3-(4,5-dimethylthiazol2-yl)-2,5-diphenyltetrazolium bromide (MTT) assay.
$10 \mu \mathrm{L}$ of MTT solution was added to each well. The cells were incubated again for $4 \mathrm{~h}$ at $37^{\circ} \mathrm{C}$ with MTT reagent. After incubation, the medium was carefully removed. The formazan crystals were dissolved in DMSO and the absorbance was measured at $570 \mathrm{~nm}$. The relative cell viability was calculated by comparing the optical density (OD) at $570 \mathrm{~nm}$ of samples treated cells with that of untreated control cells as given below:

Relative cell viability (\%) $=$ OD570 of the treated sample/ $\mathrm{OD}_{570}$ of the control (untreated) $\times 100$

\section{Results and Discussion UV-Vis absorption spectral studies}

UV-Vis is a useful technique to determine the size and stability of nanoparticles. Formation of AgNPs was primarily observed by UV-Vis. The color change was attributed to the surface plasmon resonance (SPR) phenomenon. The recorded UV-visible absorption spectra showed a maximum peak in the wavelength range of around 423-436 nm, as evident from Fig. 1(a), which was assigned to the SPR band for AgNPs. The role of piperine concentration on the synthesis of nanoparticles was investigated by adding different concentrations of piperine solutions to $1 \mathrm{mmol}$ of $\mathrm{AgNO}_{3}$ (Fig. 1(a)). The synthesis of AgNPs was also examined by using piperine $(0.5 \%)$ solution at different time intervals such as 15, 30, 45, 60 and 75 min (Fig. 1(b)). The absorbance value of the band increased with increasing time period, which indicated the continued reduction of metal ions and increase in concentration of nanoparticles. The formation of AgNPs started within $15 \mathrm{~min}$, and then the intensity of peak increased up to $75 \mathrm{~min}$.
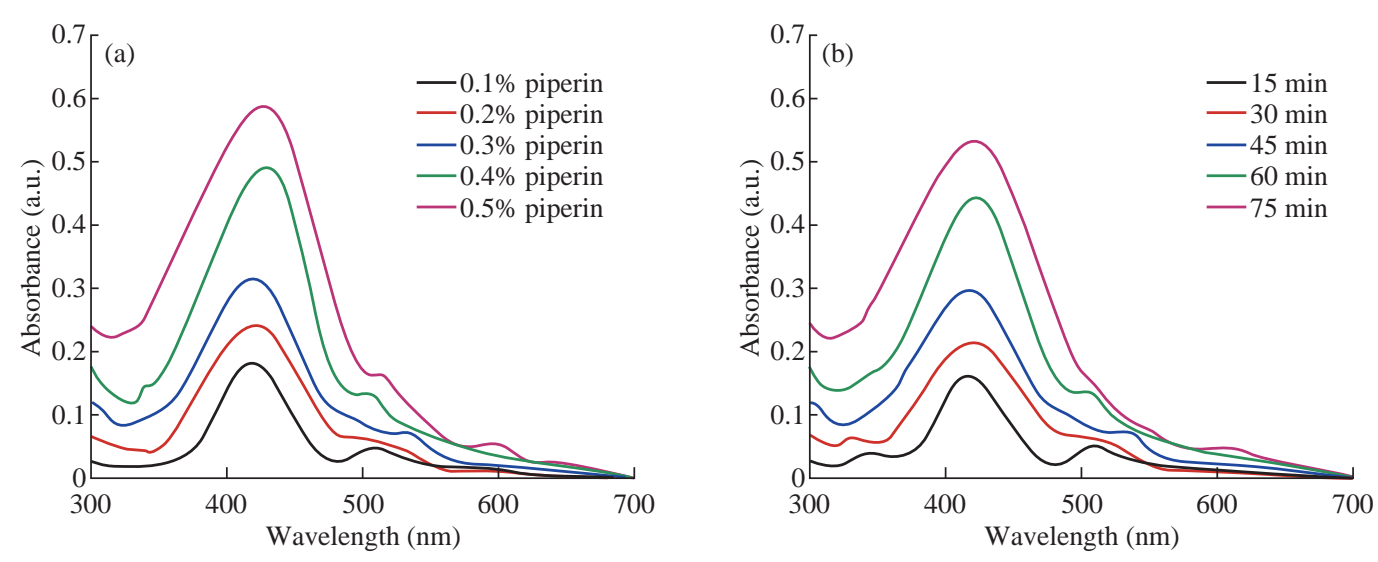

Fig. 1 Absorption spectra of (a) different concentrations of Triton X-100/piperine/AgNPs solutions; and (b) different time intervals of Triton X-100/piperine/AgNPs. 

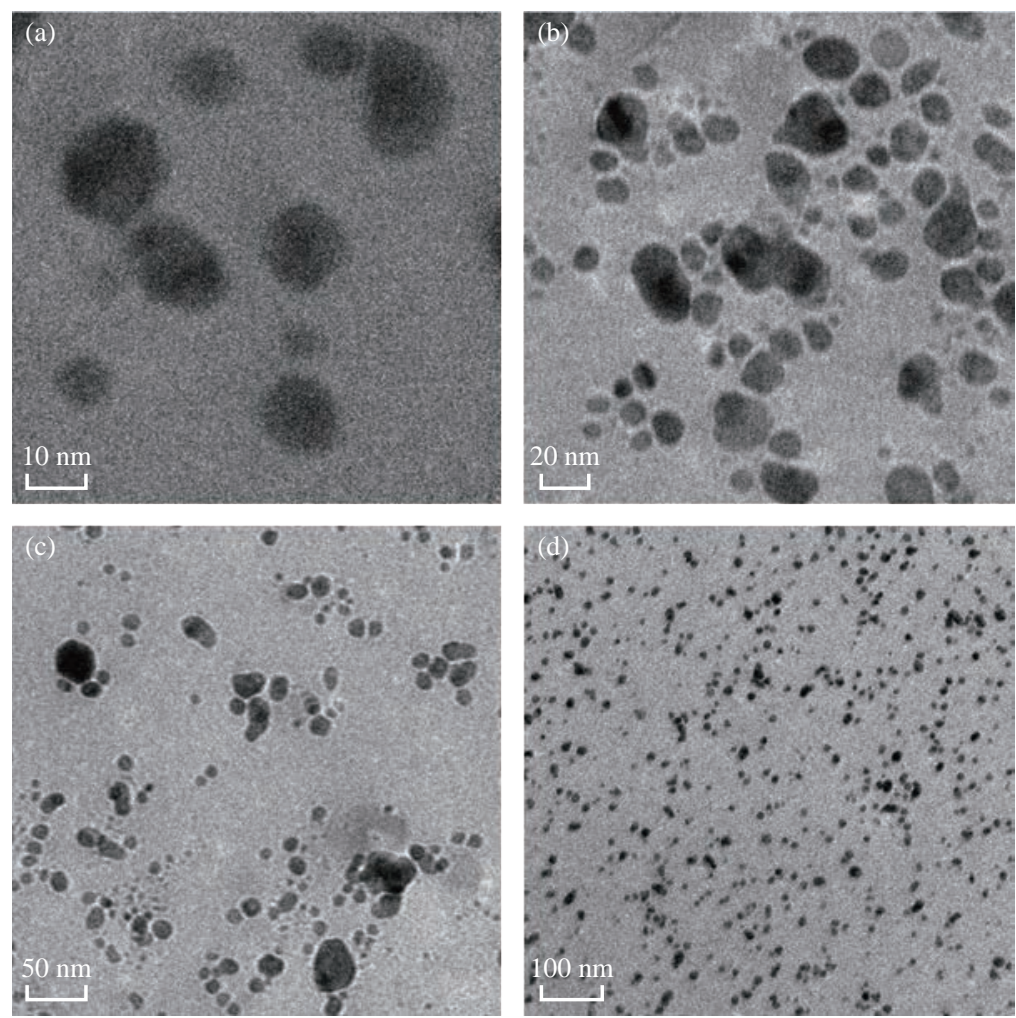

Fig. 2 (a)-(d) TEM images of Triton X-100/piperine/AgNPs.

\section{TEM, EDX and SAED pattern studies}

The TEM images of Triton X-100/piperine/AgNPs are shown in Fig. 2(a)-(d). The nanoparticles were uniformly dispersed and spherical in shape with an average size of 5-20 nm (Fig. 3). The AgNPs were predominantly spherical in shape and the nanoparticles were uniformly dispersed. This might possibly be due to the control in size of the AgNPs as they were protected by Triton X-100, which provided steric hindrances between neighboring nanoparticles preventing aggregation by overcoming the Van der Waals force of attraction between them. As a result, the nanoparticles were not agglomerated.

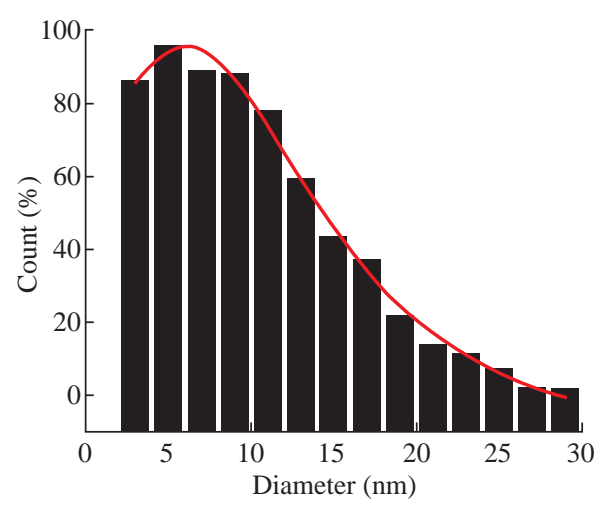

Fig. 3 Particle size distributions of Triton X-100/piperine/ AgNPs found by TEM.
The SAED pattern of the piperine-AgNPs showed ring-like diffraction pattern which indicated the amorphous nature of the nanoparticles. The diffraction circles could be indexed on the basis of the facecentered cubic (fcc) structure of silver. The diffraction patterns were assigned to the reflections from 111, 200, 220 and 311 lattice planes of fcc silver (Fig. 4(a)). The lattice planes of piperine/AgNPs were evident by sharp Braggs reflections observed in the PXRD spectrum.

The elemental composition of the piperine/AgNPs after the centrifugation and washing was determined through EDX analysis. Area-profile analysis of the synthesized nanoparticles showed strong peaks of Ag (Fig. 4(b)) at $3.3 \mathrm{keV}$. It was most likely that the $\mathrm{Si}, \mathrm{Cu}$ and $\mathrm{O}$ signals in the EDX spectrum were due to X-ray emission from proteins bound to the AgNPs surface.

\section{PXRD analysis}

The PXRD pattern of the piperine/AgNPs showed four main characteristic Bragg diffraction peaks positioned at $2 \theta$ values of $38.11,44.27,64.42$ and 77.47 degrees (Fig. 5). All these reflections corresponded to 111, 200 and 220 facets of the fcc structure of AgNPs. The diffraction peaks were consistent with standard database files (Joint Committee on Powder Diffraction Standards (JCPDS) card No. 04-0783), indicating that 

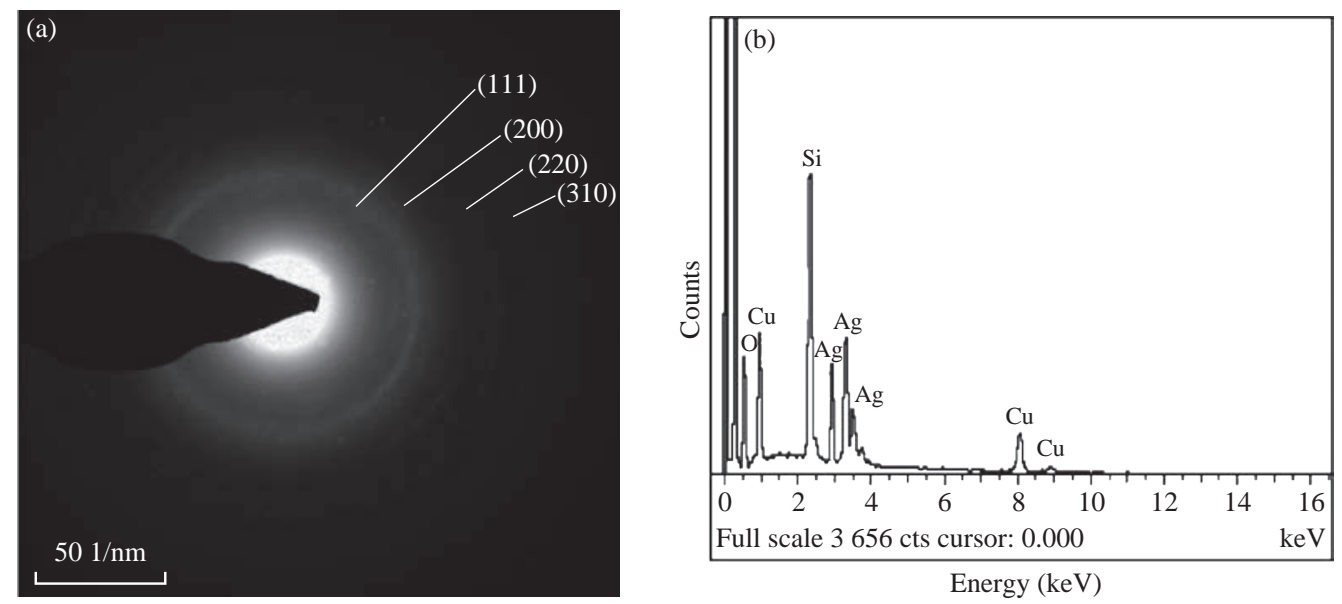

Fig. 4 (a) SAED pattern of Triton X-100-piperine-AgNPs and (b) EDX spectrum of Triton X-100/piperine/AgNPs.

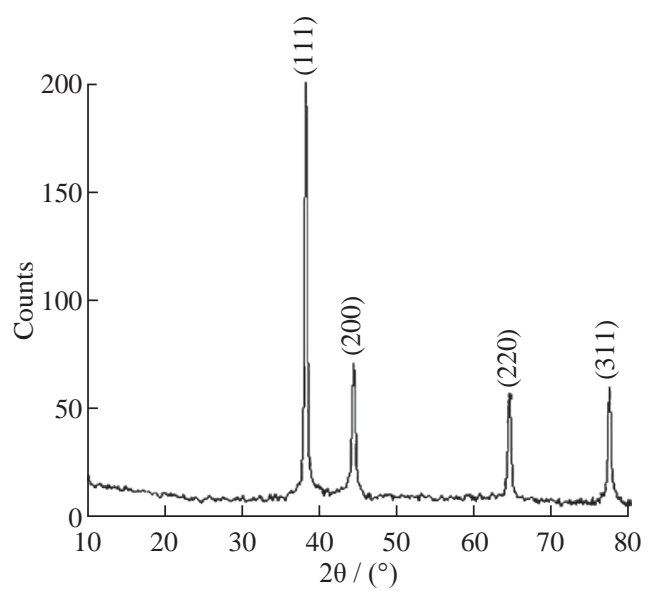

Fig. 5 PXRD pattern of Triton X-100/piperine/AgNPs.

the synthesized nanoparticles were of pure crystalline nature. The size of Triton X-100/piperine/AgNPs was evaluated from the PXRD data using the DebyeScherrer equation, $d=k \lambda / \beta \cos \theta$, and the particle size was $15 \mathrm{~nm}$.

\section{Antibacterial activity}

The antibacterial activities of the Triton X-100/ piperine with AgNPs were evaluated against the grampositive and gram-negative bacteria, S. aureus (Fig. 6(A)) and E. coli (Fig. 6(B)). The antibacterial activity was quantitatively evaluated by determination of the minimum inhibitory concentrations (MICs). Solutions with different concentrations of Triton X-100/piperine with AgNPs (10 to $250 \mu \mathrm{g} / \mathrm{mL}$ ) completely inhibited the growth of E. coli and S. aureus, respectively, the gram-positive bacteria were more susceptible to the AgNPs compared to gram-negative bacteria. Fig. 6 shows the inhibition zones of Triton X-100/AgNPs against $S$. aureus and E. coli, determined by the disk diffusion test. Apparently, the inhibitory properties of Triton X-100/piperine with AgNPs against grampositive $S$. aureus were better than those against gram-

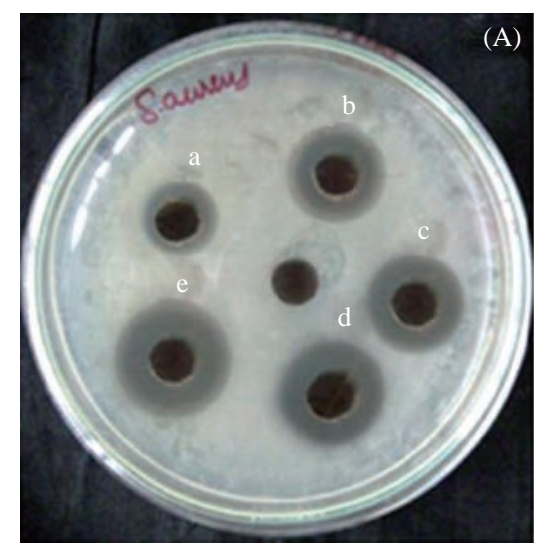

S. aureus

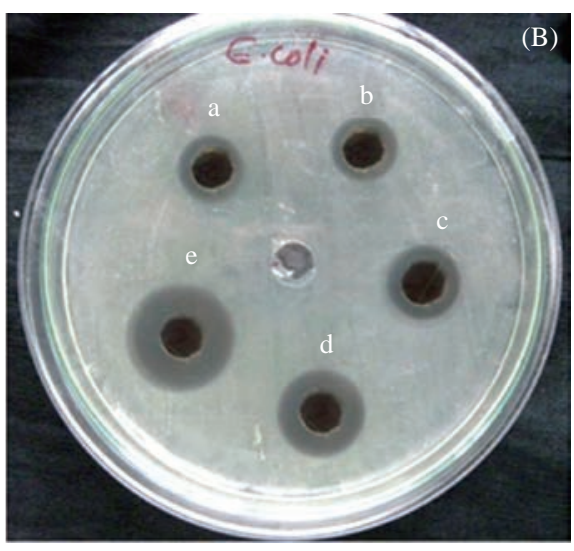

E. coli

Fig. 6 Zone inhibition produced by Triton X-100/piperine/AgNPs of (A) S. aureus and (B) E. coli at (a) 10, (b) 25, (c) 50, (d) 100 and (e) $250 \mu \mathrm{g} / \mathrm{mL}$ of concentrations. 
negative $E$. coli, which was consistent with the MIC results. Meanwhile, expansion of the inhibition zones was observed as the silver concentration increased. Triton X-100/piperine/AgNPs exhibited a dosedependent antibacterial effect on both of the tested strains. Meanwhile, the Triton X-100 (control) solution exhibited fairly weak inhibitory properties as the control. Thus, it was obvious that the antibacterial activity of Triton X-100/piperine/AgNPs was mainly attributable to the AgNPs rather than Triton $\mathrm{X}-100$, although both of these were considered to be antibacterial. The mechanisms of antibacterial activity of AgNPs are by binding on the membrane of microorganisms through electrostatic interactions, cell wall disrupts and affects the intracellular processes such as DNA, RNA and protein synthesis [24-27].

\section{In vitro cytotoxicity effects of Triton X-100/ piperine/AgNPs on HepG2 cells}

Previous studies have shown that the cytotoxic effects of AgNPs were mainly expressed by the growth of the inhibition zone and induction of apoptosis of cells [28-30]. In this study, we supposed that the cytotoxicity of Triton X-100/piperine with AgNPs may be improved by the stabilization effect of Triton $\mathrm{X}-100$. The MTT assay was used to quantitatively evaluate the cytotoxicity of Triton X-100-piperine at different concentrations. Fig. 7 shows that the relative cell viabilities of HepG2 cells decreased with the concentrations of AgNPs. These results for the cell viability assay reveal a low cytotoxic effect of Triton X-100-piperine with AgNPs cells when the concentration is from $10 \mu \mathrm{g} / \mathrm{ml}$ to $250 \mu \mathrm{g} / \mathrm{ml}$. According to the MIC determination, Triton X-100piperine-AgNPs at concentrations of 100 and 250 $\mu \mathrm{g} / \mathrm{ml}$ completely inhibited the growth of $E$. coli and $S$. aureus, respectively. Thus, the effective toxic concentration of silver towards bacteria is significantly lower than that towards HepG2 cells. It is obvious that the cytotoxic effects of Triton X-100-piperine with AgNPs were improved by the stabilization effect of Triton X-100. Therefore, Triton X-100-piperine-AgNPs within a proper concentration range is able to exert a potent antibacterial activity.

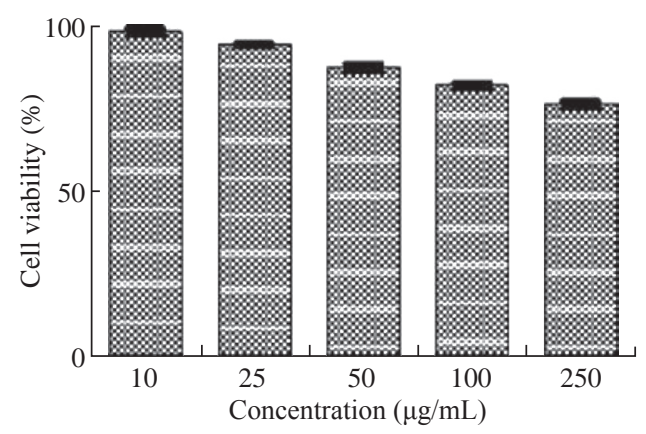

Fig. 7 Cell viability assay of Triton X-100-piperine-AgNPs.
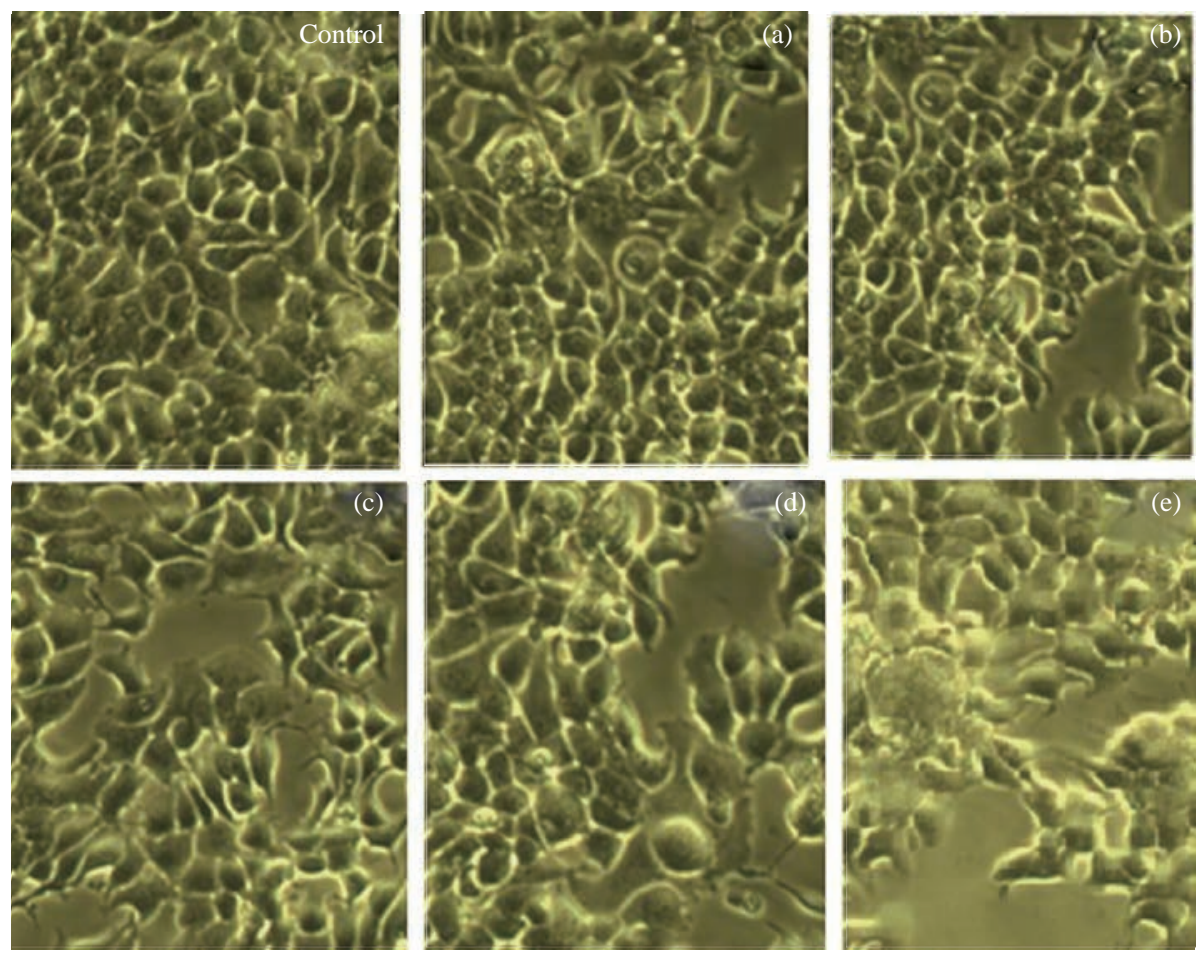

Fig. 8 The cellular morphologies of Hep-G2 cell images at (a) $10 \mu \mathrm{g} / \mathrm{mL}$, (b) $25 \mu \mathrm{g} / \mathrm{mL}$, (c) $50 \mu \mathrm{g} / \mathrm{mL}$, (d) $100 \mu \mathrm{g} / \mathrm{mL}$ and (e) 250 $\mu \mathrm{g} / \mathrm{mL}$ of Triton X-100/piperine/AgNPs. 
The MTT assay was utilized to qualitatively assess the cell viability of HepG2 cells after treatment with Triton X-100/piperine with AgNPs at different concentrations. As shown in Fig. 8, the viable cells exhibited fabric counter surface, while the dead cells exhibited plain surface. Fig. 8(a) \& (b) show similar proportions of viable cells in samples treated with 10 and $25 \mu \mathrm{g} / \mathrm{mL}$ of Triton X-100/piperine/AgNPs. As shown in Fig. 8(c) and (d), the proportions of viable cells slightly decreased to approximately $90 \%$ after treatment with 50 and $100 \mu \mathrm{g} / \mathrm{mL}$ of Triton X-100/ piperine/AgNPs. Fig. 8(e) shows that the proportion of viable cells in the sample treated with $250 \mu \mathrm{g} / \mathrm{mL}$ of Triton X-100/piperine/AgNPs dropped significantly to approximately $65 \%$. Apparently, the proportions of viable cells decreased in a dose-dependent manner, indicating that an increase in the silver concentration enhanced the cytotoxicity.

\section{Conclusions}

In this study, Triton X-100 was a nonionic surfactant and $\mathrm{AgNO}_{3}$ was successfully used for the green synthesis of AgNPs. Piperine acted as a reducing agent while Triton X-100 acted as a stabilizing agent during the preparation process. The green chemical approach using the piperine isolated from the black pepper and characterized by the UV-Vis, TEM, EDX and PXRD techniques. The UV-visible absorption spectra showed the absorption maxima as around 423-436 $\mathrm{nm}$. The TEM analysis confirmed that the AgNPs were about 5-20 nm in diameter. The PXRD confirmed a crystallite size of $15 \mathrm{~nm}$. The resulting Triton X-100/piperine/ AgNPs showed significant potential in biological and antibacterial fields. On one hand, Triton X-100/ piperine with AgNPs inhibited the growth of E. coli and $S$. aureus due to the excellent dispersibility of the AgNPs. On the other hand, the cytotoxic effect of Triton X-100/piperine with AgNPs on HepG2 cells was improved by the stabilization effect of Triton X-100. The effective toxic concentration of Triton X-100/ piperine with AgNPs towards E. coli and S. aureus was significantly lower than that towards HepG2 cells. The results demonstrated that Triton X-100/piperine/AgNPs could be a potential candidate for use in biological and pharmaceutical fields to prevent infections caused by microorganisms.

\section{Conflict of Interests}

The authors declare that there are no conflicts of interests in publishing this research article

\section{References}

[1] Y. Cheng, F. Wang, C. Fang, et al., Preparation and characterization of size and morphology controllable silver nanoparticles by citrate and tannic acid combined reduction at a low temperature. Journal of Alloys and Compounds, 2016, 658: 684-688.

[2] E.A. Jun, K.M. Lim, K. Kim, et al., Silver nanoparticles enhance thrombus formation through increased platelet aggregation and procoagulant activity. Nanotoxicology, 2011, 5: 157-197.

[3] F. Franck, K.S. Morley, W. Ben, et al., Silver nanoparticles and polymeric medical devices: a new approach to prevention of infection? Journal of Antimicrobial Chemotherapy, 2004, 54: 1019-1024.

[4] C. Dipankar, S. Murugan, The green synthesis, characterization and evaluation of the biological activities of silver nanoparticles synthesized from Iresine herbstii leaf aqueous extracts. Colloids and Surfaces B: Biointerfaces, 2012, 98: 112-119.

[5] N. Asare, C. Instanes, W.J. Sandberg, et al., Cytotoxic and genotoxic effects of silver nanoparticles in testicular cells. Toxicology, 2012, 291: 65-72.

[6] P.W. Li, T.H. Kuo, J.H. Chang, et al., Induction of cytotoxicity and apoptosis in mouse blastocysts by silver nanoparticles. Toxicology Letters, 2010, 197: 82-87.

[7] B. Liu, X. Li, C. Zheng, et al., Facile and green synthesis of silver nanoparticles in quaternized carboxymethyl chitosan solution. Nanotechnology, 2013, 24: 235601.

[8] M. Ghaedi, M. Youse nejad, M. Safarpoor, et al., Rosmarinus officinalis leaf extract mediated green synthesis of silver nanoparticles and investigation of its antimicrobial properties. Journal of Industrial and Engineering Chemistry, 2015, 31: 167-172.

[9] A.A. Kajani, A.K. Bordbar, S.H. Zarkesh Esfahani, et al., Green synthesis of anisotropic silver nanoparticles with potent anticancer activity using Taxus baccata extract. RSC Advances, 2014, 4: 61394-61403.

[10] K. Reena, P. Balashanmugam, M. Gajendiran, et al., Synthesis of Leucas Aspera Extract Loaded Gold-PLAPEG-PLA Amphiphilic Copolymer Nanoconjugates: In Vitro Cytotoxicity and Anti-Inflammatory Activity Studies. Journal of Nanoscience and Nanotechnology, 2016, 16: 4762-4770.

[11] K. Reena, M. Gajendiran, M. Prabakaran, et al., Caffeineloaded gold nanoparticles conjugated with PLA-PEG-PLA copolymer for in vitro cytotoxicity and anti-inflammatory activity. Journal of Industrial and Engineering Chemistry, 2017, 51: 113-121.

[12] K. Reena, M. Prabakaran, B. Leeba, et al., Green Synthesis of Pectin-Gold-PLA-PEG-PLA Nanoconjugates: In Vitro Cytotoxicity and Anti-Inflammatory Activity, Journal of Nanoscience and Nanotechnology, 2017, 17: 4549-4557.

[13] K. Wei, W. Li, K. Koike, et al., New amide alkaloids from the roots of Piper nigrum. Journal of Natural Products, 2004, 67: 1005-1009.

[14] K. Wei, W. Li, K. Koike, et al., Nigramides A-S, Dimeric Amide Alkaloids from the Roots of Piper nigrum. Journal of Organic Chemistry, 2005, 70, 1164-1176.

[15] K. Shanmugapriya, P.S. Saravana, H. Payal, et al., Antioxidant potential of pepper (Piper nigrum Linn.) leaves and its antimicrobial potential against some pathogenic microbes. Indian Journal of Natural Products Resources, 2012, 3: 570-577.

[16] B.J. Hudson, Food antioxidants (Elsevier and applied science series). Springer, 1990: 65-98. 
[17] R. Augustine, N. Kalarikkal, S. Thomas et al., A facile and rapid method for the black pepper leaf mediated green synthesis of silver nanoparticles and the antimicrobial study. Applied Nanoscience, 2014, 4: 809-818.

[18] B.L.V. Prasad, S.K. Arumugam, T. Bala, et al., Solventadaptable silver nanoparticles. Langmuir, 2005, 21: 822826.

[19] A. Kumar, S. Mandal, P.R. Selvakannan, et al., Investigation into the Interaction between Surface-Bound Alkylamines and Gold Nanoparticles. Langmuir, 2003, 19: 6277-6282.

[20] Z. Yan, R. Bao, C.Z. Dinu, et al., Laser ablation induced agglomeration of $\mathrm{Cu}$ nanoparticles in sodium dodecyl sulfate aqueous solution. Journal of Optoelectronics and Advanced Materials, 2010, 12: 437-439.

[21] F.D. Pelle, A. Scroccarello, M. Sergi, et al., Simple and rapid silver nanoparticles based antioxidant capacity assays: Reactivity study for phenolic compounds. Food Chemistry, 2018, 256: 342-349.

[22] S.V. Kumar, A.P. Bafana, P. Pawar, et al., High conversion synthesis of $<10 \mathrm{~nm}$ starch-stabilized silver nanoparticles using microwave technology. Scientific Reports, 2018, 8: 5106.

[23] I.A. Holder, S.T. Boyce, Agar well diffusion assay testing of bacterial susceptibility to various antimicrobials in concentrations non-toxic for human cells in culture. Burns, 1994, 20: 426-429.

[24] Z. Wang, J. Chen, P. Yang et al., Biomimetic synthesis of gold nanoparticles and their aggregates using a polypeptide sequence. Applied Organometallic Chemistry, 2007, 21: 645-651.
[25] Y. Wang, X. He, K. Wang, et al., Barbated Skullcup herb extract-mediated biosynthesis of gold nanoparticles and its primary application in electrochemistry. Colloids and Surfaces B: Biointerfaces, 2009, 73: 75-79.

[26] S.W.P. Wijnhoven, W.J.G. M. Peijnenburg, C. A. Herberts, et al., Nano-silver - a review of available data and knowledge gaps in human and environmental risk assessment. Nanotoxicology, 2009, 3: 109-138.

[27] S.S. Yudha, D. Notriawan, E. Angasa, et al., Green synthesis of silver nanoparticles using aqueous rinds extract of Brucea javanica (L.) Merr at ambient temperature. Materials Letters, 2013, 97: 181-183.

[28] N. Asare, C. Instanes, W.J. Sandberg, et al., Cytotoxic and genotoxic effects of silver nanoparticles in testicular cells. Toxicology, 2012, 291: 65-72.

[29] P.W. Li, T.H. Kuo, J.H. Chang, et al., Induction of cytotoxicity and apoptosis in mouse blastocysts by silver nanoparticles. Toxicology Letters, 2010, 197: 82-87.

[30] S. Hackenberg, A. Scherzed, M. Kessler, et al., Silver nanoparticles: evaluation of DNA damage, toxicity and functional impairment in human mesenchymal stem cells. Toxicology Letters, 2011, 201: 27-33.

Copyright $@$ Muthusamy Prabakaran, Vellaikannu Kalaiarasi, Periakaruppan Nithya, Mani Gajendiran, and Susaimanickam Arul Antony. This is an open-access article distributed under the terms of the Creative Commons Attribution License, which permits unrestricted use, distribution, and reproduction in any medium, provided the original author and source are credited. 